\title{
Comparison of test methods estimating the stiffness of ultrathin coatings
}

\author{
Marcus Vinícius Tavares da Costa ${ }^{\circledR}$, Cristian Neagu, Pierre Fayet, Urban Wiklund, Hu Li, Klaus Leifer, \\ E. Kristofer Gamstedt 1
}

(C) The Author(s) 2018

\begin{abstract}
A key engineering parameter of thin coatings is their stiffness. Stiffness characterization of ultrathin coatings with a nanometer scale thickness is experimentally challenging. In this work, three feasible methods have been used to estimate the Young's modulus of metal coatings on polymer films. The methods are: (1) nanoindentation, (2) strain-induced elastic buckling and (3) peak-force measurements integrated in atomic force microscopy. The samples were prepared by atomic layer deposition of $\mathrm{TiO}_{2}(6$ and $20 \mathrm{~nm}$ thick) and mixed oxides of $\mathrm{TiO}_{2}$ and $\mathrm{Al}_{2} \mathrm{O}_{3}$ (4 and $20 \mathrm{~nm}$ thick). The differences in estimated Young's modulus are interpreted in terms of the underlying assumptions and test conditions. Their specific advantages and drawbacks are also compared and discussed. In particular, the nanoindentation necessitates a sufficiently sharp indenter tip to make localized
\end{abstract}

This paper was presented at the 13th Coatings Science International Conference (COSI) on June 26-30, 2017, in Noordwijk, The Netherlands

M. V. Tavares da Costa, E. K. Gamstedt $(\bowtie)$

Division of Applied Mechanics, Department of Engineering

Sciences, Uppsala University, Box 534, 75121 Uppsala,

Sweden

e-mail: kristofer.gamstedt@angstrom.uu.se

M. V. Tavares da Costa

e-mail: marcus.tavares@angstrom.uu.se

C. Neagu

Tetra Pak AB, DSO Packaging Materials, Ruben Rausings

Gata, 22186 Lund, Sweden

P. Fayet

Adhemon Sarl, Thin Technology, Avenue Edouard-Dapples

20, 1006 Lausanne, Switzerland

U. Wiklund, H. Li, K. Leifer

Division of Applied Materials Science, Department of

Engineering Sciences, Uppsala University, Box 534,

75121 Uppsala, Sweden measurements dominated by the coating. The straininduced elastic buckling method is simple in practice, but showed a large scatter due to variation in local coating thickness and irregular deformation patterns. The stiffness characterization using atomic force microscopy gave the most consistent results, due to a sharp tip with a radius comparable to the thinnest coating thickness. All methods gave a higher Young's modulus for the $\mathrm{TiO}_{2}$ coating than for the mixed oxide coating, with a variation within one order of magnitude between the methods.

Keywords Nano coating, Young's modulus, Polymer substrate

\section{Introduction}

Carton food packages are indeed an important invention. Every day, billions of liters of water, milk, juice and other liquid foods are consumed around the world. Carton packaging is mostly used to contain and protect beverages so that they can be transported to the consumers with increased lifetime. The barrier function is today mainly assured by aluminum foils. This material protects food from the outside (intrusion of oxygen, humidity, etc.), as well as prevents leakage by keeping the nutrients inside. ${ }^{1}$ One of the potential candidates which can replace aluminum foil is a thin metal oxide brittle coating deposited on a polymer film substrate. ${ }^{2}$ A number of material properties are typically of interest in coatings development. One of these properties is the stiffness, which affects the strain and stress state in coating structures. It is needed in the estimation of interfacial fracture toughness in coatings subject to mechanical loading.

There are some well-known methods to characterize coatings on polymers such as the fragmentation test. ${ }^{3}$ This test can be used to calculate the interfacial shear 
strength between coating and polymer substrate, based on the observation of crack density of the coating, as an increasing tensile strain is being applied. Analytical models have been developed to determine adhesive properties of the interface from the crack density at saturation. ${ }^{4}$ Finite element simulation has also been used for the coating/substrate assemblies to determine the cohesive fracture toughness of the interface. ${ }^{5,6}$ To use these analytical or numerical approaches, it is first necessary to determine the elastic properties of the coating. Most coatings are assumed to be isotropic, and the foremost parameter is then the Young's modulus, $E$, since the Poisson ratio, $v$, does not show as much variation and has less influence on adhesive behavior. The determination of coating Young's modulus is of particular interest for thin coatings, where it is known to depend on the coating thickness.

The focus of this work is therefore to investigate the Young's modulus of thin metal oxide coating using independent methods. Three experimental methods have been used to obtain values of the Young's modulus, namely nanoindentation, mechanical buckling measurement and Peak-Force Quantitative Nanomechanical Property Mapping technique (PF-QNM). Since the ultrathin coatings (thickness in the order of $10 \mathrm{~nm}$ ) do not allow for stiffness characterization by in-plane tensile testing, all three methods are based on local out-of-plane deformations. Using three complementary characterization methods for the same material also gives the opportunity to compare the methods in practice and identify the different advantages and drawbacks of the methods for the present class of coating materials. Furthermore, this work also seeks to determine the mechanical properties of coating alternatives to aluminum and their thickness dependency.

\section{Materials and methods}

\section{Samples}

The materials in this study were selected based on their barrier function for carton food packages. All coatings were deposited by atomic layer deposition (ALD) on polymer film substrate. The materials of these coatings are $\mathrm{TiO}_{2}$ (titanium oxide) and MOX (mixed oxide, composed of even contributions of $\mathrm{TiO}_{2}$ and $\mathrm{Al}_{2} \mathrm{O}_{3}$ ). The thickness of these coatings was $20 \mathrm{~nm}$ for the thicker coatings of both materials, $4 \mathrm{~nm}$ for the thin MOX coating and $6 \mathrm{~nm}$ for the thin $\mathrm{TiO}_{2}$. The thickness was determined by the number of deposition cycles since only one atomic layer is produced for each cycle. The substrate, biaxially oriented polyethylene terephthalate (BoPET) film 120- $\mu$ m-thick Teijin Melinex ST504 from Dupont, was the same for all barrier coatings. The thickness of the coating is negligible compared with the thickness of the substrate, and the in-plane stiffness of the coated film is therefore entirely dominated by the stiffness of the substrate.

\section{Tensile testing}

The Young's modulus of the substrate was obtained by tensile test from the slope of the initial linear regime of the stress-strain diagram. Three tests were carried out for each barrier coating. The influence of the ultrathin coating on the film stiffness was substantially smaller than the measurement scatter. The samples were cut in small pieces with dimensions $4 \mathrm{~mm} \times 20 \mathrm{~mm}$ using scalpel and ruler. The samples were stretched up to $40 \%$ of nominal strain, the speed was $0.1 \mathrm{~mm} / \mathrm{min}$, and the gauge length was $>10 \mathrm{~mm}$. All data were measured by the Deben "Microtest" tensile stage, and the scatter was taken as the standard deviation of the test results.

\section{Nanoindentation}

The main principle of this technique is the nanoscale indentation of a rigid indenter into the surface of a deformable material. From the load-deflection curve of the unloading phase, the elastic properties close to the surface can be obtained. ${ }^{8}$ The CSM Ultra Nano Hardness Tester with a diamond cube corner indenter of $40 \mathrm{~nm}$ tip radius was used for all ALD samples. At the time of testing, this was the sharpest tip available for this particular nanoindentation device. The indentation depth was up to $30 \mathrm{~nm}$. The loading rate was chosen to be $100 \mu \mathrm{N} / \mathrm{min}$, as a compromise to be slow enough to obtain stable data and fast enough to avoid viscous effects. A holding time of $10 \mathrm{~s}$ before unloading was chosen to let the material set, and thus avoid viscous effects in the unloading curve. 9 The sample size was around $5 \mathrm{~mm} \times 5 \mathrm{~mm}$, and 10 indentations were made for each sample from which the average Young's modulus of the coating was calculated. Each specimen was attached using double-sided adhesive tape on top of the horizontal sample holder. The influence of the adhesive tape was neglected since the indentation depth was extremely shallow. The contact stiffness was experimentally measured from the initial portion of unloading curve ${ }^{10,11}$

$S=\left(\frac{d P}{d h}\right)_{\max }=m P_{\max }\left(h_{\max }-h_{\mathrm{p}}\right)^{-1}=\beta \frac{2}{\sqrt{\pi}} E_{\mathrm{r}} \sqrt{A}$

where $E_{\mathrm{r}}$ is the reduced modulus, $A$ is the projected area, $h_{\max }-h_{\mathrm{p}}$ is the total penetration depth, $P_{\max }$ is the maximum force, and $m$ and $\beta$ are constants which depend on the geometry of the indenter. The value of $\beta$ was set to 1.0 for a hemispherical indenter, ${ }^{11}$ and the projected area $A$ and constant $m$ were experimentally calibrated by the nanoindentation device. The calibration of $A$ accounts for the assumed spherical tip. Once the reduced modulus $E_{\mathrm{r}}$ is known, the Young's modulus of the coating, $E_{\mathrm{c}}$, is obtained through $^{9-12}$ 
$E_{\mathrm{c}}=\frac{1-v_{\mathrm{c}}}{\frac{1}{E_{\mathrm{r}}}-\frac{1-v_{\mathrm{i}}}{E_{\mathrm{i}}}}$

where $E_{i}$ is the Young's modulus of the indenter, 1145 $\mathrm{GPa}$. The Poisson ratios of the indenter and coating, $v_{\mathrm{i}}$ and $v_{\mathrm{c}}$ are 0.070 and 0.30 , respectively, for the diamond indenter ${ }^{8}$ and titanium and aluminum oxide coatings. $^{13}$

\section{Strain-induced elastic buckling instability for mechanical measurement}

The phenomenon of elastic buckling instability of a superficial coating subjected to in-plane compressive strains can be instrumental in estimating the stiffness of the coating. This kind of test is usually abbreviated SIEBIMM in the literature, denoting strain-induced elastic buckling instability for mechanical measurement. The principle is to measure the buckling wavelength caused by an applied or residual compressive strain on coating/substrate-film. The analytical modeling typically requires that (1) the stiffness of the coating is much higher than that of the substrate, $E_{\mathrm{c}} \gg E_{\mathrm{s}}$, (2) the substrate is thicker than the coating, $h_{\mathrm{s}} \gg h_{\mathrm{c}}$, and (3) the buckling takes place in the small strain regime. Figure 1 shows schematically how the buckles appear as well as the important dimensions in the cross section. In our case, a tensile strain was applied and, due to the Poisson effect (quantified by $v_{\mathrm{c}}$ and $\left.v_{\mathrm{s}}\right)$, the elastic buckling forms by an effective lateral contraction force $F$.

A practical approach has been developed by Volynskii et al., ${ }^{14}$ where they reported the mechanism of buckling formation in the gold layer of $10 \mathrm{~nm}$ thick on PET substrate and derived the relation for the wavelength

$\lambda=2 \pi h_{\mathrm{c}} \sqrt[3]{\frac{\left(1-v_{\mathrm{s}}^{2}\right) E_{\mathrm{c}}}{3\left(1-v_{\mathrm{c}}^{2}\right) E_{\mathrm{s}}}}$

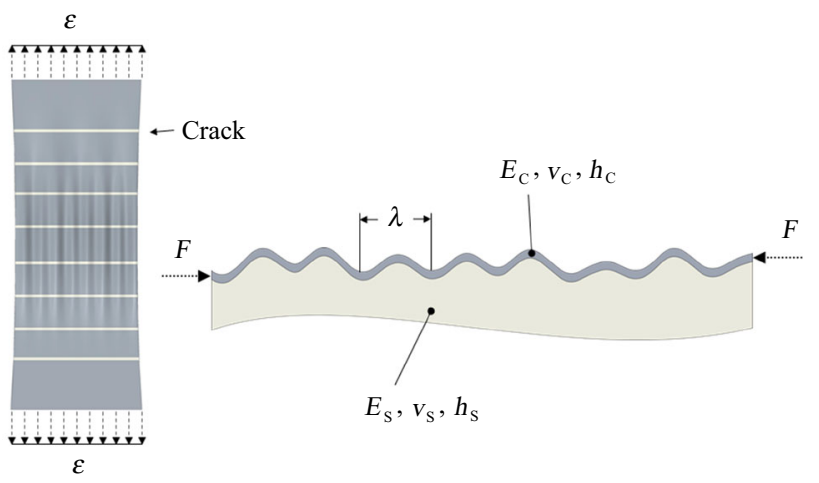

Fig. 1: Buckling formation due to an effective compressive force (Poisson effect) in a coated film caused by an applied tensile strain as a function of the thickness of the coating, $h_{\mathrm{c}}$, the Young's modulus and Poisson's ratios of the coating and the substrate using Euler derivative equation.

Later, Stafford et al. ${ }^{15}$ used this equation to determine the Young's modulus of the coating using a designed tensile stage with laser diffraction to measure the wavelength of the buckled coating. Solving for $E_{\mathrm{c}}$ gives SIEBIMM main equation

$$
E_{\mathrm{c}}=\frac{3}{8 \pi^{3}} E_{\mathrm{s}} \frac{1-v_{\mathrm{c}}^{2}}{1-v_{\mathrm{s}}^{2}}\left(\frac{\lambda}{h_{\mathrm{c}}}\right)^{3} .
$$

A state of plane strain is assumed. In our case, the Poisson ratios $v_{\mathrm{c}}$ and $v_{\mathrm{s}}$ are $0.30^{13}$ and $0.44,{ }^{1}$ respectively. Equation (4) was also used, e.g., by Cranston et al. ${ }^{16}$ to determine the Young's modulus of thin films $(\sim 70 \mathrm{~nm})$ of nanofibrillated cellulose multilayers using a tensile microtest stage together with scanning electron microscopy (SEM). Such studies show that SIEBIMM may be effective for elastic characterization of thin layers.

It should be noted that equation (4) is applicable only for small deformations. Jiang et al. ${ }^{17}$ proposed a correction of equation (3) for the case of finite deformation in buckling due to substrate prestraining. By use of their approach, a corrected wavelength $\lambda_{0}$ can be calculated

$\lambda_{0}=\lambda\left(1+\varepsilon_{\mathrm{T}}\right)(1+\xi)^{1 / 3}$

where

$\xi=5 \varepsilon_{\mathrm{T}}\left(1+\varepsilon_{\mathrm{T}}\right) / 32$.

The compressive transverse strain, $\varepsilon_{\mathrm{T}}=-v_{\mathrm{s}} \varepsilon_{\lambda}$, is determined from the applied longitudinal tensile strain at buckling onset $\varepsilon_{\lambda}$. The buckling strain $\varepsilon_{\lambda}$ and the wavelength $\lambda$ are obtained experimentally.

In this study, four SIEBIMM tests were carried out in situ in a Deben "Microtest" tensile stage installed in a Hitachi TM-1000 table-top SEM operating at $15 \mathrm{kV}$ with a backscattered electron detector. For high magnification, the specimen was subsequently brought to a Zeiss Merlin field emission gun SEM used at an acceleration voltage of $2 \mathrm{kV}$ and the high-efficiency secondary electron (HE-SE2) detector suited for detailed topographic analysis. The considered coatings were made from nonconductive materials. Consequently, unwanted charging effects were observed in the SEM during the first attempts. In order to reduce the charging effects, all these samples were coated on top of barrier layers with $\mathrm{Au}-\mathrm{Pd}$ conductive coating by Quorum SC7640 polaron sputter coater.

The effects of the $\mathrm{Au}-\mathrm{Pd}$ coating on the mechanical experiments are presented in Appendix A. In these tests, the coating properties were examined in the lateral direction, measuring the buckling size before and after the conductive layer, and longitudinal direc- 
tion, observing the cracking progress regarding tensile strain in different $\mathrm{Au}-\mathrm{Pd}$ thicknesses. Essentially, it could not be demonstrated that the conductive coating had any influence on the estimation of coating stiffness.

Figure 2 illustrates how the SIEBMM test was performed. A removable rig was designed and manufactured to fit the Deben tensile stage in the vacuum chamber of the table-top SEM, as shown in Fig. 2a. When the buckling was clearly observed in situ during tensile testing in the SEM, the loading was stopped and the applied strain in the sample was fastened by tightening two fixation screws in the removable rig, as shown in Fig. 2b. The compact rig was then detached and taken to the high-resolution SEM. The removable rig can thus swiftly be taken out from the microtensile stage and moved to a high-resolution SEM while maintaining the tensile strain at buckling onset $\varepsilon_{\lambda}$, as shown in Fig. 2c.

\section{AFM peak-force measurements}

The Young's modulus of the coatings was also estimated using a Multimode 8 Atomic Force Microscope, Bruker, in the Peak-Force Quantitative Nanomechanical Mapping (PF-QNM) mode. ${ }^{12,18}$ A silicon probe was utilized with the tip radius of $8 \mathrm{~nm}$. PF-QNM mode is a technique to quantitatively measure the surface mechanical properties of the sample by recording the force-separation feedback loop in the AFM as illustrated in Fig. 3. The Young's modulus, the adhesion force, energy dissipation and the sample deformation can be extracted from this loop, where the Young's modulus can be estimated by fitting the retraction part of the force-separation loop to the Derjaguin-Muller-Toporov (DMT) $\operatorname{model}^{19}$ :

$F-F_{\mathrm{adh}}=\frac{4}{3} E_{\mathrm{r}}^{\mathrm{AFM}} \sqrt{R\left(d-d_{0}\right)^{3}}$ where $F-F_{\text {adh }}$ is the difference between the force on the cantilever and the adhesion force, $R$ is the tip radius, $E_{\mathrm{r}}^{\mathrm{AFM}}$ is the reduced modulus, and $d-d_{0}$ is the sample deformation. Just as for nanoindentation, the Young's modulus of the coating is calculated from the reduced modulus by equation (2).

\section{Results and discussion}

\section{Tensile testing}

The in-plane tensile test confirmed that there was no influence of the coating stiffness on the film stiffness, which was effectively dominated by the substrate. The obtained value of the Young's modulus of the substrate was comparable for all samples, and no tangible difference was found compared with the same substrate material without any barrier coating. ${ }^{20}$ That also

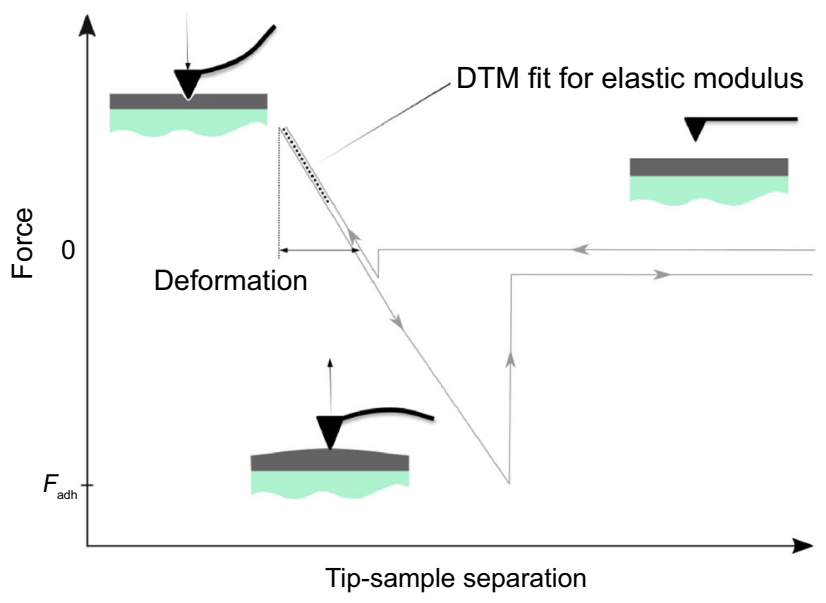

Fig. 3: Force-separation curve generated in AFM PF-QNM mode

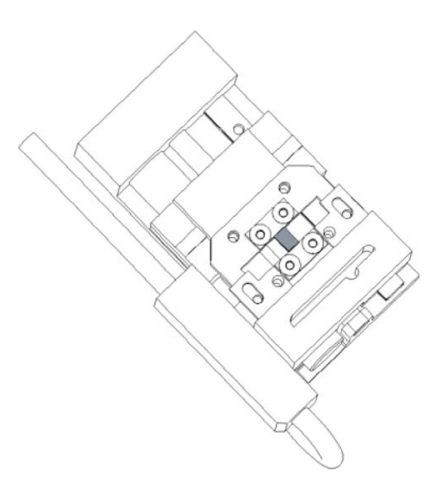

(a)

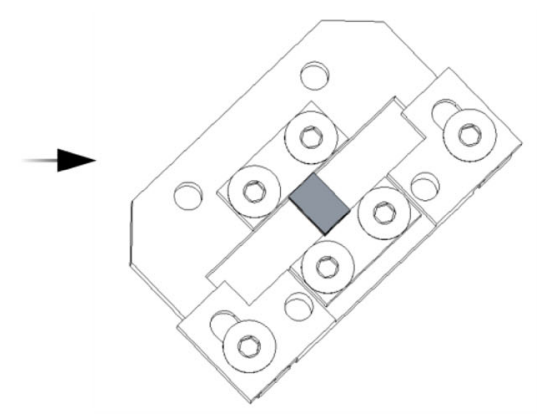

(b)

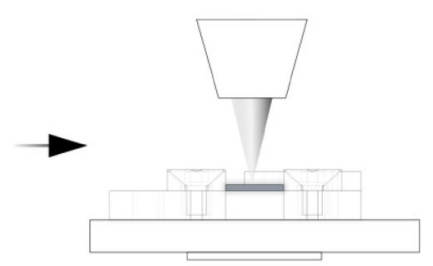

(c)

Fig. 2: Steps in the elastic buckling instability analysis: (a) The removable rig attached in tensile stage. (b) The fixation rig which is dismounted at the point of buckling formation. (c) The rig is brought to a high-resolution SEM for measurement of the buckle dimensions 
shows that the ALD manufacturing process did not change the elastic property of the polymer substrate. Figure 4 shows the results from tensile test.

\section{Nanoindentation}

The contact stiffness was determined by least squares fitting from unloading curves starting at $98 \%$ down to $40 \%$ of the maximum measured force. With a holding time of $10 \mathrm{~s}$ before unloading, obvious viscous effects could be avoided. Figure 5 shows the results from the

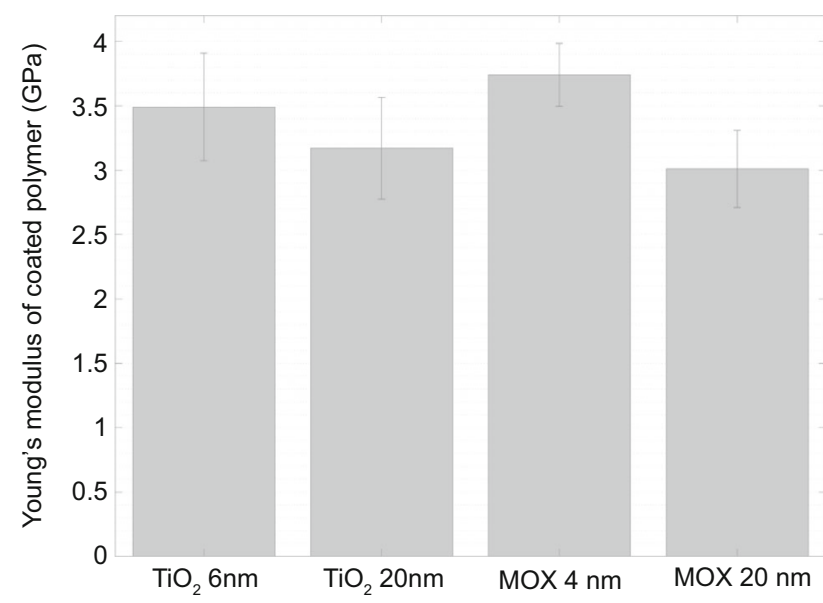

Fig. 4: Young's modulus of the coated substrate determined from tensile testing

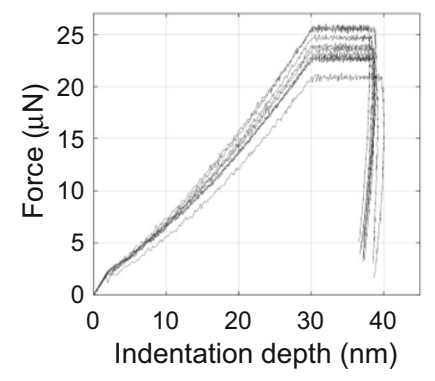

(a)

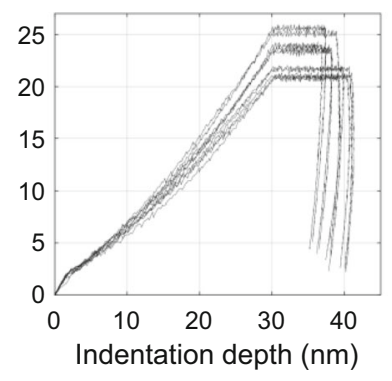

(b)

nanoindentation tests, from which the coating Young's moduli were determined using equations (1) and (2) as an average from 10 measurements. These values are summarized in Table 1 together with those from the other independent test methods. For some indentations, in particular for the thinner coatings, viscous effects due to the polymer substrate were apparent. This resulted occasionally in nearly vertical unloading curves in the force-indentation diagrams.

\section{SIEBIMM}

The buckling formation was observed in situ by SEM. The strain for onset of buckling could then be determined. It was noticed that the strains for initial buckling showed a significant variation, since the elastic instability was controlled by the local thickness and elastic properties. A high tensile strain at buckling onset was observed for the thinner $\mathrm{TiO}_{2}$ and MOX coatings of 0.31 and 0.42 , respectively. For $20-\mathrm{nm}$ coatings, the buckling was perceptible at tensile strain of 0.1. Occasionally, cracks were found along the ridges of the larger buckles (see Fig. 6). The wavelength of the cracked buckles was, however, found to be the same as with the uncracked ones. If a band of adjacent buckles could not be found, the local wavelength of localized buckles was measured.

Figure 6 shows the buckles on top of a $\mathrm{TiO}_{2}$ coating of $6 \mathrm{~nm}$ strained at 0.31 in the longitudinal direction. This image was taken from the center of the sample, where the load was relatively uniform. This region had

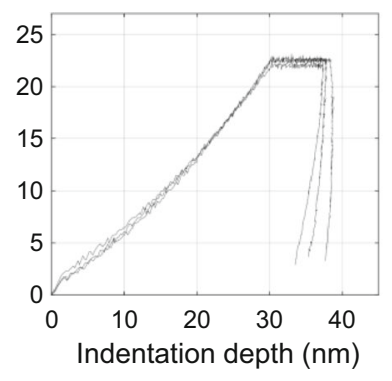

(c)

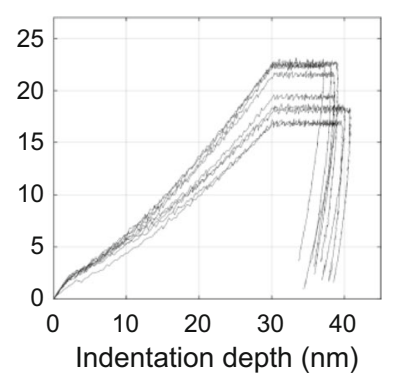

(d)

Fig. 5: Force versus indentation depth in nanoindentation of the coatings. (a) $\mathrm{TiO}_{2} 6 \mathrm{~nm},(\mathrm{~b}) \mathrm{TiO}_{2} 20 \mathrm{~nm}$, (c) $\mathrm{MOX} 4 \mathrm{~nm}$, (d) MOX $20 \mathrm{~nm}$

Table 1: Summary of estimated Young's moduli for the characterization methods

\begin{tabular}{llllll} 
Barrier coating & $h_{\mathrm{c}}(\mathrm{nm})$ & $\begin{array}{c}\text { Tensile test } \\
E_{\mathrm{s}}(\mathrm{GPa})\end{array}$ & $\begin{array}{c}\text { Nanoindentation } \\
E_{\mathrm{c}}(\mathrm{GPa})\end{array}$ & $\begin{array}{c}\text { AFM } \\
E_{\mathrm{c}}(\mathrm{GPa})\end{array}$ & $\begin{array}{c}\text { SIEBIMM } \\
E_{\mathrm{c}}(\mathrm{GPa})\end{array}$ \\
\hline $\mathrm{TiO}_{2}$ & 6 & $3.5 \pm 0.4$ & $44 \pm 19$ & $45 \pm 2$ & $420 \pm 140$ \\
$\mathrm{TiO}_{2}$ & 20 & $3.2 \pm 0.4$ & $35 \pm 17$ & $76 \pm 2$ & $64 \pm 16$ \\
$\mathrm{MOX}$ & 4 & $3.7 \pm 0.2$ & $31 \pm 21$ & $29 \pm 2$ & $240 \pm 110$ \\
$\mathrm{MOX}$ & 20 & $3.0 \pm 0.3$ & $23 \pm 09$ & $43 \pm 3$ & $52 \pm 13$ \\
\hline
\end{tabular}


a high and relatively uniform concentration of buckles. The wavelength pattern was different that those reported by Stafford et al., ${ }^{15}$ Volynskii et al. ${ }^{14}$ and Cranston et al. ${ }^{16}$ The buckling process is influenced by the stiffness ratio $E_{\mathrm{c}} / E_{\mathrm{s}}$, according to equation (3). The reported values ranged in the order $10^{3}-10^{5}$, whereas in this study, the ratio is in the range of 7-25.

All coatings had similar buckling shapes, but showed different dimensions. The size of all buckles was measured in SEM, and then averaged to calculate the coating Young's modulus $E_{\mathrm{c}}$ using equation (4).The values are reported in Table 1.

\section{AFM peak-force measurement}

The indentation depth in AFM was controlled within a few $\mathrm{nm}$ by a sharp AFM tip (radius of $8 \mathrm{~nm}$ ), resulting in a limited influence from the substrate, which is suitable for ultrathin coating measurement. Figure 7 shows the effective Young's modulus maps of an area approximately $1 \mu \mathrm{m}^{2}$ for each barrier coating. Each pixel in the AFM images corresponds to a loop described previously in Fig. 3. Each image is made up of more than 250,000 measurements. The measured force deformations for all pixels were used to determine the average Young's modulus of the coating by means of equations (2) and (5).

The average values of each coating are reported in Table 1.

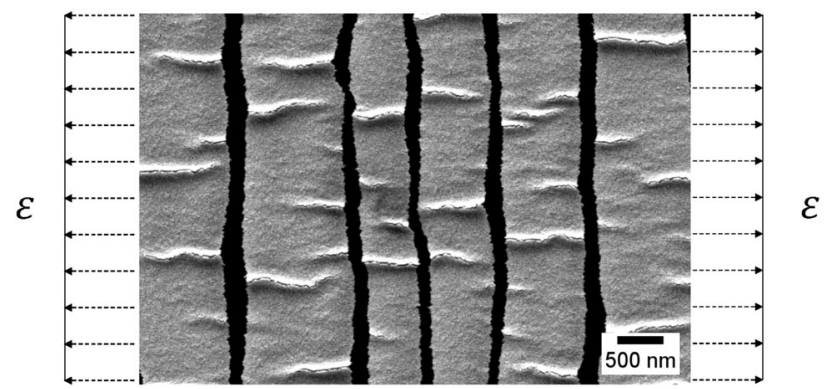

Fig. 6: SEM image of a $\mathrm{TiO}_{2}$ coating of $6 \mathrm{~nm}$ stretched at 0.31 strain

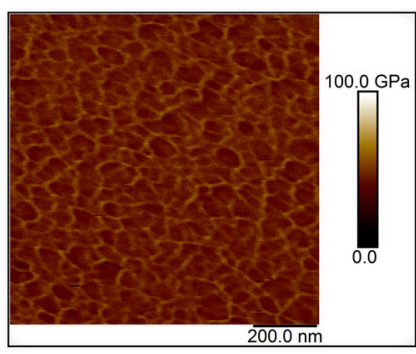

(a)

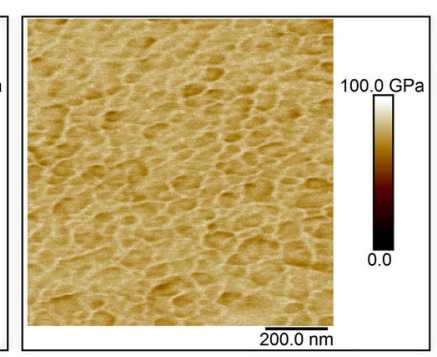

(b)

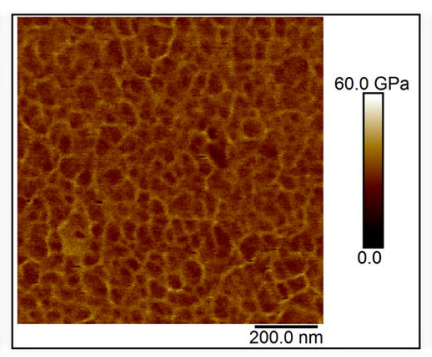

(c)

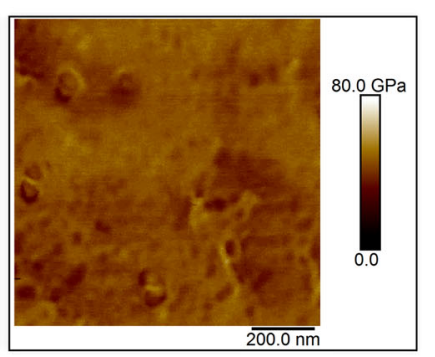

(d)

Fig. 7: AFM mapping of the effective Young's modulus of the coatings. (a) $\mathrm{TiO}_{2} 6 \mathrm{~nm}$, (b) $\mathrm{TiO}_{2} 20 \mathrm{~nm}$, (c) $\mathrm{MOX} 4 \mathrm{~nm}$, (d) MOX $20 \mathrm{~nm}$ 
Pharr, ${ }^{22}$ Hay/Crawford ${ }^{23}$ and King ${ }^{21}$ models. These models were developed in a range of hundred nanometers of coating thickness and depend of normalized contact area over coating thickness. It turned out that the values of the coating modulus did not improve.

The buckling method, SIEBIMM, has the advantage of being straightforward, not requiring an advanced apparatus to measure local loads and displacements. In our case, the buckles appeared at relatively high strains, where the polymer substrate was subject to some inelastic deformation. The moduli estimated using this method were much larger than those from the other methods. With a fully elastic and relatively compliant substrate, such as an elastomer, the clarity of the buckles and the calculated stiffness values would most likely be improved.

The AFM method showed the most consistent results compared with the other methods. In this case, the tip radius was much smaller than that used in nanoindentation, which provides better local deformation. For nanoindentation, it is likely pushing the coating down rather than being measured from a point load at a pyramidal tip (Oliver Pharr method). Additionally, the indentation depth in AFM is small enough to have only a limited influence of the viscoelastic polymer substrate. A considerable amount of stiffness data is generated, since the AFM equipment automatically maps a given area. This leads to average values of higher statistical confidence compared with few pointwise measurements in nanoindentation.

Although the variation was large in absolute numbers, all methods showed the same trend with a higher Young's modulus for the $\mathrm{TiO}_{2}$ coating than for the MOX coating $\left(\mathrm{TiO}_{2}\right.$ and $\mathrm{Al}_{2} \mathrm{O}_{3}$ mixture). This is consistent with Cherneva et al., ${ }^{24}$ who measured a slightly higher modulus for $\mathrm{TiO}_{2}$ than for $\mathrm{Al}_{2} \mathrm{O}_{3}$.

The influence of the coating thickness on Young's modulus of the coating was not conclusive. The AFM method showed a higher stiffness for the thicker coating, whereas the other methods showed the reverse order, which was also found by Chen et al. ${ }^{7}$

To estimate Young's modulus of coatings with a thickness of less than $0.1 \mu \mathrm{m}$ is indeed challenging. The present paper presents a number of candidate methods, each with their specific advantages and drawbacks. Both AFM and nanoindentation are based on pushing in and retracting a rigid tip. AFM allows for more shallow indentation, which makes it more suitable for very thin coatings. The advantage of SIEBIMM is its simplicity since only the wavelength of coating buckles needs to be measured, but it relies on elastic reversible deformation at relatively high strains which is not always feasible. Overall, all presented methods still show potential to rank the stiffness properties of thin coatings. Quantitative measures are, however, needed, e.g., in models predicting the fragmentation of strained brittle coatings.
Acknowledgments Financial support and supply of the test samples for this study by Tetra Pak Packaging Solutions AB, Development and Service Operations (DSO), are much appreciated. MVTdC is grateful to the European Commission within the framework of the Erasmus Mundus Programme, Action 2-STRAND 1, Lot 9, Brazil for PhD studies. The authors would like to thank Mr. Luimar Correa for the technical assistance in the SEM experiments and Dr. Jessica Bolinsson for valuable scientific discussions.

Open Access This article is distributed under the terms of the Creative Commons Attribution 4.0 International License (http://creativecommons.org/lice nses/by/4.0/), which permits unrestricted use, distribution, and reproduction in any medium, provided you give appropriate credit to the original author(s) and the source, provide a link to the Creative Commons license, and indicate if changes were made.

\section{Appendix A: Effects of the conductive layer in the barrier coating properties}

Observation of buckling caused by elastic instability in thin coatings typically requires a conductive coating in SEM analysis since the features of interest are in the sub-micron scale. In order to reduce charging effects, all the samples were coated on top of the barrier layer with a Au-Pd conductive coating by Quorum SC7640 polaron sputter coater. $\mathrm{Au}-\mathrm{Pd}$ is one of thinnest continuous coating materials for SEM purposes. ${ }^{25}$ For the deposition process the following parameters were used: an accelerate voltage of $2 \mathrm{kV}$, a plasma discharge current of $20 \mathrm{~mA}$, a pressure between 5 and $8 \mathrm{~Pa}$ and a deposition time of $1 \mathrm{~min}$. Using these parameters provides a layer of $8.5 \mathrm{~nm}$ thick, ${ }^{26}$ which was the minimum thickness allowing observation of surface buckling and fracture without excessive charging effects. The issue to address here is whether or not this additional layer would have any influence on the buckling formation and size.

To investigate the influence of the $\mathrm{Au}-\mathrm{Pd}$ coating, two different test samples were produced with the $\mathrm{TiO}_{2}$ $20-\mathrm{nm}$ coating. In the first one, the sample was stretched up to a strain level of 0.12 , where the buckles were clearly observed and then $\mathrm{Au}-\mathrm{Pd}$ was sputtered on top of coating. In the second one, the $\mathrm{Au}-\mathrm{Pd}$ was sputtered before the stretching at the same strain. Both test samples were observed in the SEM using an acceleration voltage of $3 \mathrm{kV}$ and the high-efficiency secondary electron HE-SE2 detector. The micrographs can be seen in Fig. 8, where (a) the precoated and (b) the post-coated samples show the same deformation 


\section{Stretching after Au-Pd coating}
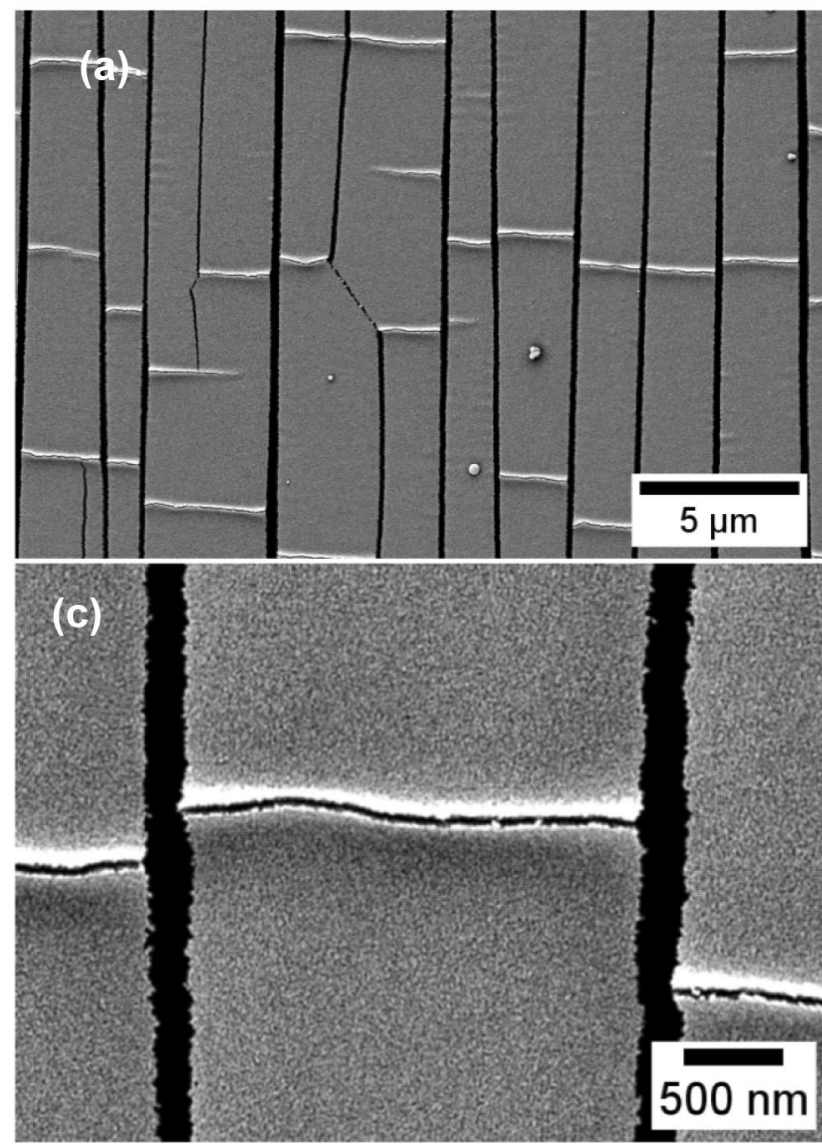
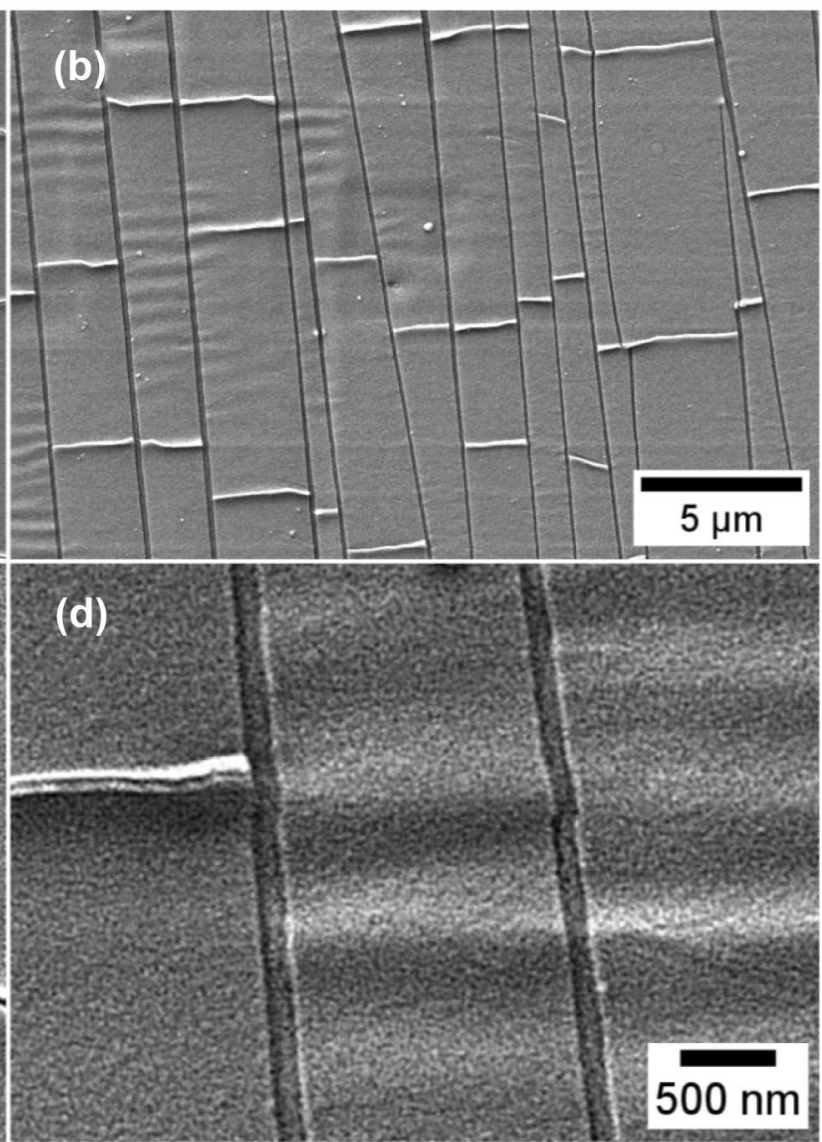

Fig. 8: Stretched samples coated with $20 \mathrm{~nm} \mathrm{TiO}_{2}$ : (a) and (c) have been deposited with a conductive Au-Pd coating before stretching, and (b) and (d) after stretching

behavior. The similarities are also found at higher magnification for (c) the precoated and (d) post-coated samples. Not only qualitatively, but also quantitatively did the dimensions of the buckles not show any significant difference if the conductive coating was applied before or after the buckling formation. It is therefore assumed that the $\mathrm{Au}-\mathrm{Pd}$ coating did not influence the mechanical behavior in the SIEBIMM test of the $\mathrm{TiO}_{2}$ coated film.

In addition, the conductive coating did not have significant influence on the fragmentation process of the brittle barrier coating in tensile loading. Figures 9 and 10 show that the crack accumulation was not influenced by the thickness of the conductive coating for the $\mathrm{MOX}$ and $\mathrm{TiO}_{2}$ films, respectively.

The Au-Pd is not a continuous monolithic material, but shows a granular structure at high magnification as shown in Fig. 11, obtained in $246 \mathrm{k} \times$ of magnification with an in-lens secondary electron detector. The $\mathrm{Au}-$ $\mathrm{Pd}$ layer has a granular structure on the polymer surface in the crack, as well as on the $\mathrm{TiO}_{2}$ barrier. If these granules are separated from each other in tension, the conductive layer cannot expect to carry much stress, which has also been pointed out by Rochat et al. ${ }^{27}$

Based on the negligible influence of the $\mathrm{Au}-\mathrm{Pd}$ coating on the buckling formation and tensile cracking of the investigated metal oxide coatings, it is assumed that the conductive coating does not have any influence in the mechanical analysis of the SIEBIMM test. The observed microstructure with separable granules in the conductive coating can be a reason for the very limited mechanical effect of the material. 
$1.5 \mathrm{~nm}$

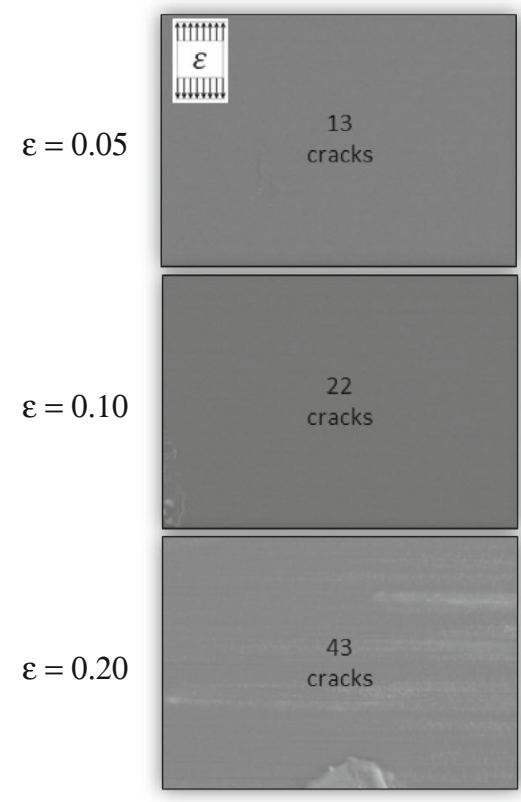

$4 \mathrm{~nm}$

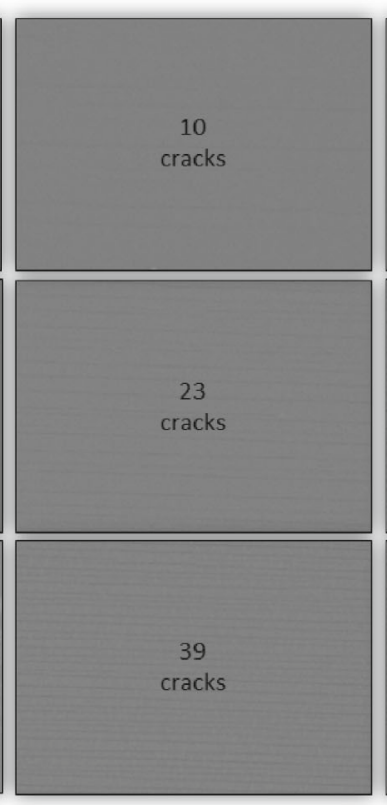

$8.5 \mathrm{~nm}$

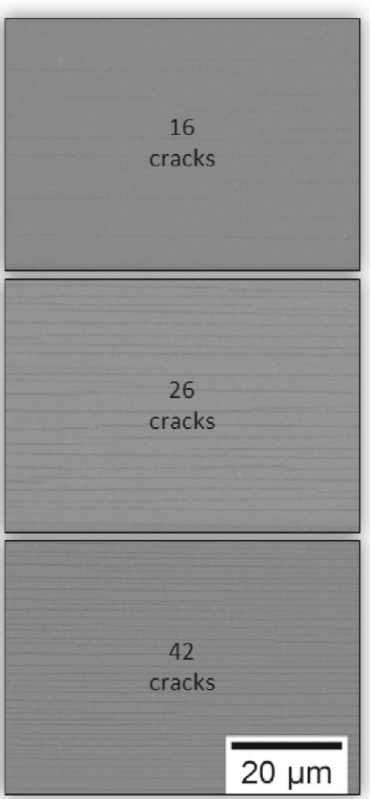

Fig. 9: SEM images showing a comparable accumulation of crack with increasing tensile strain for various thicknesses of conductive coatings on for $20 \mathrm{~nm}$ MOX films

$1.5 \mathrm{~nm}$

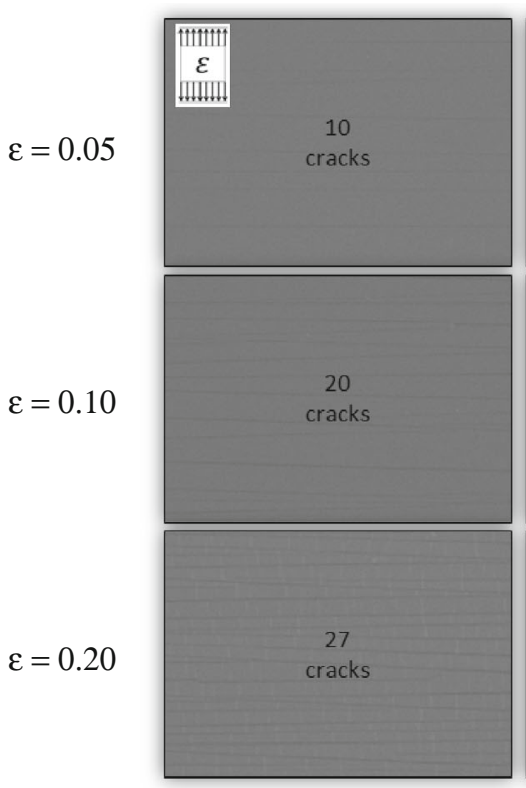

$4 \mathrm{~nm}$

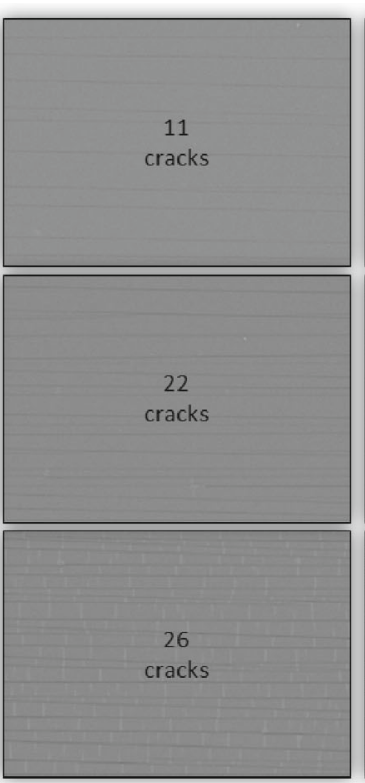

$8.5 \mathrm{~nm}$

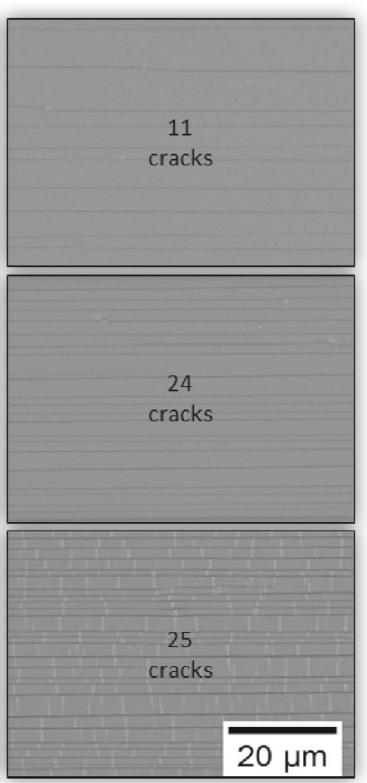

Fig. 10: SEM images showing a comparable accumulation of crack with increasing tensile strain for various thicknesses of conductive coatings on for $20 \mathrm{~nm} \mathrm{TiO}$ films 


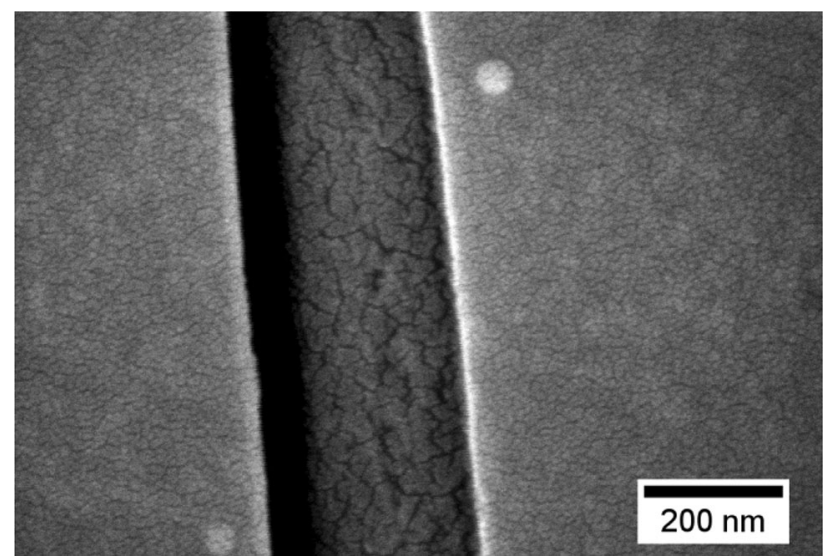

Fig. 11: High-resolution SEM image of a crack of $\mathrm{TiO}_{2}$ $20 \mathrm{~nm}$ showing the granular nanoscale structure of the $\mathrm{Au}-$ Pd coating both on the polymer substrate in the crack and on top of $\mathrm{TiO}_{2}$ layer

\section{References}

1. Fayet, P, Neagu, C, Gamstedt, K, "Mechanics-Driven Material Design for Optimized Barrier Films." Proc. The AIMCAL Web Coating and Handling Conference, Naples, USA, October 2015

2. Henry, BM, Erlat, AG, McGuigan, A, Grovenor, CRM, Briggs, GAD, Tsukahara, Y, Miyamoto, T, Noguchi, N, Niijima, T, "Characterization of Transparent Aluminium Oxide and Indium Tin Oxide Layers on Polymer Substrates." Thin Solid Films, 382 (1) 194-201 (2001)

3. Leterrier, Y, "Durability of Nanosized Oxygen-Barrier Coatings on Polymers." Prog. Mater. Sci., 48 (1) 1-55 (2003)

4. Andersons, J, Leterrier, Y, Tornare, G, Dumont, P, Månson, JAE, "Evaluation of Interfacial Stress Transfer Efficiency by Coating Fragmentation Test." Mech. Mater., 39 (9) 834-844 (2007)

5. Andersons, J, Tarasovs, S, Leterrier, Y, "Evaluation of Thin Film Adhesion to a Compliant Substrate by the Analysis of Progressive Buckling in the Fragmentation Test." Thin Solid Films, 517 (6) 2007-2011 (2009)

6. Jansson, NE, Leterrier, Y, Medico, L, Månson, J-AE, "Calculation of Adhesive and Cohesive Fracture Toughness of a Thin Brittle Coating on a Polymer Substrate." Thin Solid Films, 515 (4) 2097-2105 (2006)

7. Chen, S, Liu, L, Wang, T, "Investigation of the Mechanical Properties of Thin Films by Nanoindentation, Considering the Effects of Thickness and Different Coating-Substrate Combinations." Surf. Coat. Technol., 191 (1) 25-32 (2005)

8. Oliver, WC, Pharr, GM, "An Improved Technique for Determining Hardness and Elastic Modulus Using Load and Displacement Sensing Indentation Experiments." J. Mater. Res., 7 (6) 1564-1583 (1992)

9. Doerner, M, Nix, W, "A Method for Interpreting the Data from Depth-Sensing Indentation Instruments." J. Mater. Res., 1 (4) 601-609 (1986)

10. Sneddon, IN, "The Relation Between Load and Penetration in the Axisymmetric Boussinesq Problem for a Punch of Arbitrary Profile.” Int. J. Eng. Sci., 3 (1) 47-57 (1965)

11. Woirgard, J, Cabioc'h, T, Rivière, JP, Dargenton, JC, "Nanoindentation Characterization of SiC Coatings Prepared by Dynamic Ion Mixing." Surf. Coat. Technol., 100101 128-131 (1998)
12. Pittenger, B, Erina, N, Su, C, "Quantitative Mechanical Property Mapping at the Nanoscale with PeakForce QNM." Bruker Application Note, 128, 2012.

13. Chinmulgund, M, Inturi, RB, Barnard, JA, "Effect of Ar Gas Pressure on Growth, Structure, and Mechanical Properties of Sputtered Ti, Al, TiAl, and $\mathrm{Ti}_{3} \mathrm{Al}$ Films." Thin Solid Films, 270 (1-2) 260-263 (1995)

14. Volynskii, AL, Bazhenov, S, Lebedeva, OV, Bakeev, NF, "Mechanical Buckling Instability of Thin Coatings Deposited on Soft Polymer Substrates." J. Mater. Sci., 35 (3) 547554 (2000)

15. Stafford, CM, Harrison, C, Beers, KL, Karim, A, Amis, EJ, VanLandingham, MR, Kim, H-C, Volksen, W, Miller, RD, Simonyi, EE, "A Buckling-Based Metrology for Measuring the Elastic Moduli of Polymeric Thin Films." Nat. Mater., 3 545-550 (2004)

16. Cranston, ED, Eita, M, Johansson, E, Netrval, J, Salajková, M, Arwin, H, Wågberg, L, "Determination of Young's Modulus for Nanofibrillated Cellulose Multilayer Thin Films Using Buckling Mechanics.' Biomacromolecules, 12 (4) 961969 (2011)

17. Jiang, H, Khang, DY, Song, J, Sun, Y, Huang, Y, Rogers, JA, "Finite Deformation Mechanics in Buckled Thin Films on Compliant Supports." Proc. Natl. Acad. Sci., 104 (40) 1560715612 (2007)

18. Cai, Y, Li, H, Karlsson, M, Leifer, K, Engqvist, H, Xia, W, "Biomineralization on Single Crystalline Rutile: The Modulated Growth of Hydroxyapatite by Fibronectin in a Simulated Body Fluid." RSC Adv., 6 (42) 35507-35516 (2016)

19. Papadakis, R, Li, H, Bergman, J, Lundstedt, A, Jorner, K, Ayub, R, Haldar, S, Jahn, BO, Denisova, A, Zietz, B, Lindh, R, Sanyal, B, Grennberg, H, Leifer, K, Ottosson, H, "MetalFree Photochemical Silylations and Transfer Hydrogenations of Benzenoid Hydrocarbons and Graphene." Nat. Commun., 712962 (2016)

20. MacDonald, WA, Looney, MK, MacKerron, D, Eveson, R, Adam, R, Hashimoto, K, Rakos, K, "Latest Advances in Substrates for Flexible Electronics.” J. Soc. Inf. Disp., 15 (12) 1075-1083 (2007)

21. Saha, R, Nix, W, "Effects of the Substrate on the Determination of Thin Film Mechanical Properties by Nanoindentation." Acta Mater., 50 (1) 23-38 (2002)

22. Rar, A, Song, H, Pharr, GM, "Assessment of New Relation for the Elastic Compliance of a Film-Substrate System." MRS Proceedings, 695 (2002)

23. Hay, J, Crawford, B, "Measuring Substrate-Independent Modulus of Thin Films." J. Mater. Res., 26 (6) 727-738 (2011)

24. Cherneva, S, Iankov, R, Radic, N, Grbic, B, Stoychev, D, "Nanoindentation Investigation of Mechanical Properties of $\mathrm{ZrO}_{2}, \mathrm{ZrO}_{2}-\mathrm{Y}_{2} \mathrm{O}_{3}, \mathrm{Al}_{2} \mathrm{O}_{3}$ and $\mathrm{TiO}_{2}$ Thin Films Deposited on Stainless Steel OC 404 Substrate by Spray Pyrolysis."' Mater. Sci. Eng. B, 183 12-16 (2014)

25. Goldstein, J, Newbury, D, Joy, D, Lyman, C, Echlin, P, Lifshin, E, Sawyer, L, Michael, J, Scanning Electron Microscopy and $X$ ray Microanalysis, 3rd ed. Springer, New York (2003)

26. Quorum Technologies, "SC7680 High Resolution Sputter Coater Operating Manual." Document Number OMSC7680, Issue 2 (08/05).

27. Rochat, G, Leterrier, Y, Fayet, P, Månson, J-AE, "Mechanical Analysis of Ultrathin Oxide Coatings on Polymer Substrates In situ in a Scanning Electron Microscope." Thin Solid Films, 437 204-210 (2003) 